\title{
Circulating Insulin-Like Growth Factor I Mediates Effects of Exercise on the Brain
}

\author{
Eva Carro, ${ }^{1}$ Angel Nuñez, ${ }^{2}$ Svetlana Busiguina, ${ }^{1}$ and Ignacio Torres-Aleman ${ }^{1}$ \\ ${ }^{1}$ Laboratory of Neuroendocrinology, Cajal Institute, Consejo Superior de Investigaciones Cientificas, 28002 Madrid, Spain, \\ and 2Department of Morphology, School of Medicine, Autonoma University, 28029 Madrid, Spain
}

Physical exercise increases brain activity through mechanisms not yet known. We now report that in rats, running induces uptake of blood insulin-like growth factor I (IGF-I) by specific groups of neurons throughout the brain. Neurons accumulating IGF-I show increased spontaneous firing and a protracted increase in sensitivity to afferent stimulation. Furthermore, systemic injection of IGF-I mimicked the effects of exercise in the brain. Thus, brain uptake of IGF-I after either intracarotid injection or after exercise elicited the same pattern of neuronal accumulation of IGF-I, an identical widespread increase in neu- ronal c-Fos, and a similar stimulation of hippocampal brainderived neurotrophic factor. When uptake of IGF-I by brain cells was blocked, the exercise-induced increase on c-Fos expression was also blocked. We conclude that serum IGF-I mediates activational effects of exercise in the brain. Thus, stimulation of the uptake of blood-borne IGF-I by nerve cells may lead to novel neuroprotective strategies.

Key words: insulin-like growth factor I; exercise actions on brain function; blood-CSF pathway; neuronal activation; c-Fos; brain-derived neurotrophic factor
The roman aphorism "mens sana in corpore sano" acknowledges the well recognized positive effects of physical exercise on brain function. Recent evidence links physical activity to diverse indicators of neuronal function such as increased expression of neurotrophic factors, early response genes, or hippocampal neurogenesis (Neeper et al., 1995; Iwamoto et al., 1996; Gomez-Pinilla et al., 1997; Van Praag et al., 1999). However, the mechanisms underlying these changes are not yet known.

Insulin-like growth factor I (IGF-I) is a trophic factor that circulates at high levels in the blood-stream and mediates many of the effects of growth hormone $(\mathrm{GH})$ in the body (Jones and Clemmons, 1995). Although the main source of serum IGF-I is the liver (Yakar et al., 1999), many other tissues synthesize it and are sensitive to its trophic actions (Jones and Clemmons, 1995). In the adult brain, expression of IGF-I mRNA is circumscribed to specific locations (Werther et al., 1990), whereas IGF-I and its receptor are widespread and distributed throughout the CNS (Bondy et al., 1992).

The CSF contains IGFs and IGF-binding proteins (IGFBPs) (Ferry et al., 1999). However, epithelial cells producing the CSF in the choroid plexus (CP) do not express detectable levels of IGF-I mRNA, although they contain high levels of IGF-I receptor (Marks et al., 1991; Werther et al., 1990). These observations suggest that IGF-I from an external source may enter into the brain through the CSF pathway. Indeed, previous evidence indicates that peripheral IGF-I enters into the brain (Reinhardt and Bondy, 1994) and that IGF-I delivered into the CSF is taken up by brain cells (Fernandez-Galaz et al., 1998).

\footnotetext{
Received Oct. 7, 1999; revised Feb. 3, 2000; accepted Feb. 4, 2000.

Correspondence should be addressed to I. Torres-Aleman, Cajal Institute, CSIC, Avenida Dr. Arce 37, 28002 Madrid, Spain. E-mail: torres@cajal.csic.es.

This work was supported by grants from Direccion General de Ciencia y Tecnologia (PB97-0018) and Comunidad Autonoma de Madrid (08.5/0051.1/98). We are grateful to J. Sancho and C. Bailon for their expert help. We also thank L. M. Garcia-Segura for his excellent advice, A. Muñoz for providing the BDNF cDNA, and R. Manso for sharing the treadmill machine with us.

Copyright (C) 2000 Society for Neuroscience $\quad 0270-6474 / 00 / 202926-08 \$ 15.00 / 0$
}

If entrance of IGF-I into the brain is of any biological relevance, it must take place under physiological conditions. In this regard, it has already been reported that peripuberal surges in blood IGF-I levels (Handelsman et al., 1987) modulate hypothalamic function (Hiney et al., 1996). Because another stimulus of the GH-IGF-I axis is physical exercise (Schwarz et al., 1996), we hypothesized that blood IGF-I may also modulate brain responses to physical activity. Thus, we explored whether circulating IGF-I enters into the brain during exercise and whether this entrance impinges on neuronal function.

\section{MATERIALS AND METHODS}

Experimental procedures. Adult Wistar rats were injected either in the carotid artery (intracarotid) or in the lateral cerebral ventricle (intracerebroventricularly) under pentobarbital anesthesia $(50 \mathrm{mg} / \mathrm{kg}$, i.p.) with digoxigenin-labeled IGF-I (DIG-IGF-I). Human recombinant IGF-I (GroPep) was labeled with digoxigenin-3-O-methylcarbonyl-aminocaproic acid- $N$-hydroxy-succinimide ester (Boehringer Mannheim, Mannheim, Germany) by a procedure that renders a fully bioactive IGF-I (FernandezGalaz et al., 1998). For intracarotid injection, DIG-IGF-I $(10 \mu \mathrm{g} / \mathrm{rat}$ in $100 \mu \mathrm{l}$ saline) was injected through a cannula placed in the common carotid artery. For intracerebroventricular administration, the cannula was implanted stereotaxically into the lateral cerebral ventricle [coordinates: $-1 \mathrm{~mm}$ anteroposterior (A) from bregma, $4 \mathrm{~mm}$ ventral (V), and $1.2 \mathrm{~mm}$ lateral (L) (Paxinos and Watson, 1997)]. In blocking experiments, DIG-IGF-I $(10 \mu \mathrm{g})$ was given simultaneously with excess unlabeled IGF-I $(100 \mu \mathrm{g})$ or excess insulin $(2 \mathrm{mg})$. Controls were injected with saline. To inhibit brain uptake of IGF-I, animals received for $3 \mathrm{~d}$ an intracerebroventricular infusion containing an anti-IGF-I polyclonal antibody ( $20 \%$ in saline) plus an IGF-I receptor antagonist $(20 \mu \mathrm{g} / \mathrm{ml})$. The anti-IGF-I polyclonal antibody was produced by us and shows very high binding affinity for IGF-I, whereas the IGF-I receptor antagonist known as JB-1 has been shown by us and others to inhibit the action of IGF-I both in vivo and in vitro (Fernandez et al., 1997). As shown in Figure $1 D$, this procedure resulted in complete blockade of the entrance of IGF-I into the brain, because no IGF-I labeling was found. Control animals received saline infusions.

Growth factor assays. IGF-I levels were determined by radioimmunoassay (RIA) (Pons and Torres-Aleman, 1992). To avoid contamination of serum IGF-I with brain IGF-I measurements, rats were thoroughly perfused with saline to eliminate blood from brain tissue. CSF samples $(150 \mu \mathrm{l})$ were obtained from the cisterna magna. IGF-I mRNA levels 
were determined with an RNase protection assay (Busiguina et al., 1996). In situ hybridization for BDNF was performed with probes generated with a rat BDNF cDNA cloned in $\mathrm{pSK}^{-}$(Busiguina et al., 1996).

Treadmill running. Animals were familiarized with the treadmill apparatus (Letica) to minimize novelty stress and then divided in two groups: exercised and nonexercised. The electrical shock system that encouraged the animals to run was then disconnected to avoid pain stress. The exercise group ran for $1 \mathrm{hr}$ at $17 \mathrm{~m} / \mathrm{min}$, whereas the control group remained in the treadmill without running. Animals bearing intracerebroventricular minipumps to block IGF-I uptake ran under identical conditions. After running, the rats were deeply anesthetized and killed. Trunk blood samples were obtained, and brains were perfused (for immunocytochemistry or RIA) or snap frozen (for RNA quantitation).

Immunocytochemistry. Immunocytochemical detection was performed as described (Fernandez et al., 1999). The primary antibodies used were polyclonal anti-IGF-I (1:500), polyclonal (1:300) or monoclonal (1:200) anti-digoxigenin (Boehringer Mannheim); polyclonal anti-IGF-I receptor (1:1000), monoclonal anti-c-Fos (1:1000) (Santa Cruz Biotechnology, Santa Cruz, CA); and monoclonal anti-calbindin (1:1000) (Swant). The secondary antibodies that were used were biotinylated goat anti-mouse IgG (1:1000) (Jackson ImmunoResearch, West Grove, PA) or anti-rabbit IgG (1:250-1:1000) (Pierce, Rockford, IL). A third amplification step was used with Cy3-streptavidin (1:1000) (Jackson ImmunoResearch). For double immunocytochemistry, the rabbit and mouse primary antibodies were added simultaneously. In this case, secondary antibodies were a goat anti-rabbit IgG-Cy2 and a goat anti-mouse IgG-Cy5 (1:250) (Amersham, Arlington Heights, IL). Sections were visualized in a confocal microscope (Leica, Nussloch, Germany).

Neuronal recordings. Rats of both sexes (180-250 gm) were anesthetized with either urethane $(1.6 \mathrm{gm} / \mathrm{kg}$ i.p.; $50 \%$ of the animals $)$ or ketamine hydrochloride/xylazine (100 and $20 \mathrm{mg} / \mathrm{kg}$ i.p., respectively) to discard interferences of the anesthesia with experimental procedures. Animals were placed in a stereotaxic device, with control of end-tidal $\mathrm{CO}_{2}$ concentration. For electroencephalogram (EEG) recording, a macroelectrode $(120 \mu \mathrm{m}$ diameter) was lowered $1.5 \mathrm{~mm}$ from the cortical surface into the frontal lobe. The EEG was filtered between 0.3 and $30 \mathrm{~Hz}$ and continuously monitored in the oscilloscope. Single unit recordings were performed in the dorsal column nuclei (DCN; $n=12$ rats) and in the Purkinje cellular layer of the cerebellum $(n=11)$ by means of tungsten microelectrodes (World Precision Instruments). Microelectrodes were aimed at the gracilis [A, -13.6 to $-14.6 \mathrm{~mm}$ from bregma; $\mathrm{L}, 0.2-1.0 \mathrm{~mm} ; \mathrm{V}, 0.0-0.5 \mathrm{~mm}$ from the surface of the brain (Paxinos and Watson, 1997)] or the cuneatus nuclei [A, -13.5 to -14.5 from bregma; $\mathrm{L}, 1.5-2.5 \mathrm{~mm} ; \mathrm{V}, 0.0-0.5 \mathrm{~mm}$ from the surface of the brain (Paxinos and Watson, 1997)]. Cerebellar recordings were performed in the vermis. The vermis was exposed and covered with warmed mineral oil. Unit recordings $(0.3-3 \mathrm{kHz})$ and field potentials $(1 \mathrm{~Hz}$ to $3 \mathrm{kHz})$ were filtered, amplified, and fed to a Macintosh computer (sample frequency $10 \mathrm{kHz}$ ) for off-line analysis. Somatosensory stimulation of DCN cells was performed by an electronically gated probe $(1 \mathrm{~mm}$ diameter, $20 \mathrm{msec}$ duration) delivered at $0.5 \mathrm{~Hz}$ on either the forelimbs or hindlimbs. Parallel fiber electrical stimulation was performed with a bipolar electrode placed on the cerebellar surface $(50-100 \mu \mathrm{A} ; 0.1-0.3 \mathrm{msec})$. Statistical analysis of the recorded signals was performed with Spike 2 software (Cambridge Electronic Design). Summed peristimulus time histograms (PSTHs) were calculated, using 2 msec bin widths. Averages of the cerebellar field potentials evoked by parallel fiber stimulation were also calculated. All data are shown as mean \pm SE. Statistical analysis was performed with a nonparametric Wilcoxon test. All experiments were performed in accordance with European Community Council regulations.

\section{RESULTS}

\section{Systemic injection of IGF-I mimics the effects of exercise on the brain}

Because protective actions of blood-borne IGF-I were found in brain-injured rats (Fernandez et al., 1998), we determined whether passage of blood IGF-I into the brain would also take place under physiological conditions such as during exerciseinduced activation of the GH-IGF-I axis. As shown in Figure $1 \mathrm{~A}$, $1 \mathrm{hr}$ of treadmill running induced profuse labeling of different brain areas with IGF-I, whereas nonexercised control animals show no brain IGF-I labeling (Fig. $1 B, a$ ). IGF-I-positive cells were found in areas of the cortex, hippocampus, striatum, septum, thalamus, hypothalamus, cerebellum, red nucleus, and several brain stem nuclei (most prominently the inferior olive, reticular, and gracilis and cuneatus nuclei). Most cells accumulating IGF-I are calbindin positive (Fig. $2 A$ ), which together with their typical neuronal morphology makes us consider them as neurons.

To ascertain whether exercise-induced IGF-I labeling of brain cells was caused by uptake of IGF-I from serum, we first determined whether systemic administration of IGF-I results also in its accumulation by brain cells. As shown in Figure $1 A$, intracarotid injection of digoxigenin-labeled IGF-I (10 $\mu \mathrm{g}$ per rat) resulted in IGF-I staining of the same brain areas labeled with IGF-I after physical exercise. Double-staining of the cells showed that labeled neurons contained digoxigenin-labeled IGF-I because both IGF-I and digoxigenin colocalized in the same neurons (Fig. $1 B$ ). Serum levels of IGF-I were not modified by either running or intracarotid injection of IGF-I: $9 \pm 0.9 \mathrm{ng} / \mathrm{ml}$ after $1 \mathrm{hr}$ of exercise $(n=$ 6), $11.4 \pm 0.4 \mathrm{ng} / \mathrm{ml}$ after $1 \mathrm{hr}$ of intracarotid injection of IGF-I $(n=6)$, and $8.9 \pm 0.4 \mathrm{ng} / \mathrm{ml}$ in saline-injected controls $(n=6)$.

Does injection of exogenous IGF-I mimic the effects of exercise on the brain? As illustrated in Figure $1 C$, both exercise and intracarotid injection of IGF-I elicited the same pattern of increased c-Fos staining throughout the CNS. Colocalization analysis of c-Fos and IGF-I indicated that only a minority of the neurons expressing c-Fos also accumulated IGF-I (Table 1). In addition, a similar increase in hippocampal expression of BDNF mRNA was found in animals subjected to $1 \mathrm{hr}$ of treadmill running (Neeper et al., 1995) and in animals receiving an intracarotid injection of IGF-I $1 \mathrm{hr}$ before being killed (Fig. 1E).

To determine whether entrance of IGF-I into the brain is a critical intermediary of exercise actions on the brain, we blocked the uptake of IGF-I by brain cells before animals were subjected to $1 \mathrm{hr}$ of treadmill running. Chronic administration into the CSF of an anti-IGF-I antibody plus an IGF-I receptor antagonist (JB-1) resulted in blockade of IGF-I entrance into the brain after exercise, as determined by absence of brain labeling with IGF-I (Fig. 1D). Importantly, this procedure resulted also in blockade of the exercise-induced c-Fos staining of brain cells (Fig. 1D).

\section{Entrance of blood-borne IGF-I into the brain}

The previous results suggested that increased labeling of IGF-I in the brain after either exercise or intracarotid injection may be caused by increased uptake of serum IGF-I by brain cells. Thus, we determined whether brain IGF-I levels increase after exercise or intracarotid injection of IGF-I. As shown in Figure 2D, running for $1 \mathrm{hr}$ elicited a significant increase in brain IGF-I levels (35\% over controls, $p<0.05 ; n=6$ ), whereas $1 \mathrm{hr}$ after intracarotid injection of IGF-I (10 $\mu \mathrm{g})$, a smaller increase was also found $(22 \%$ over controls, $p=0.05 ; n=6)$. Although these increases in brain IGF-I appear to be less pronounced than those found by immunocytochemistry (compare Fig. $2 D$ with Fig. $1 A$ ), the latter technique does not reflect quantitative changes. In addition, brain IGF-I mRNA levels were not altered by exercise (data not shown).

Uptake of blood-borne IGF-I by neurons follows a timedependent pattern. Brain labeling was found $5 \mathrm{~min}$ after injection of IGF-I and remained for several hours (Fig. 2C). Uptake of blood-borne DIG-IGF-I was a saturable process because labeling was completely blocked by simultaneous intracarotid injection of excess unlabeled IGF-I (100 $\mu \mathrm{g}$ per rat) (Fig. $2 B)$. On the contrary, insulin, a peptide with close structural homology to IGF-I, did not completely block neuronal labeling even at very high doses (Fig. 2B). Although insulin also enters into the brain after 


\section{IGF-I}
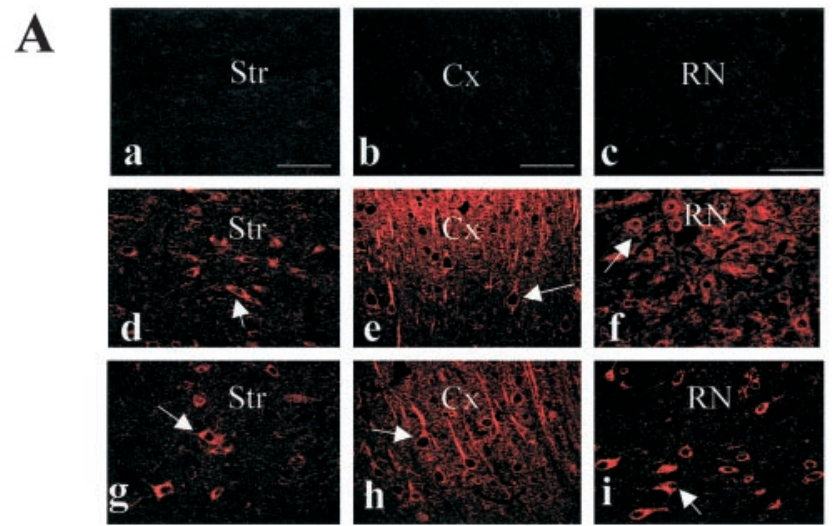

D
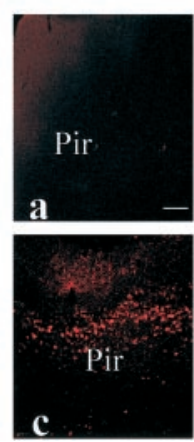

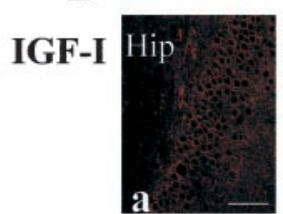

c-Fos

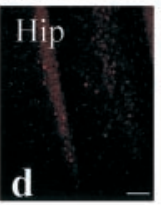

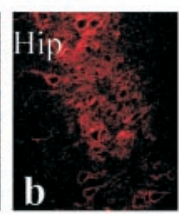
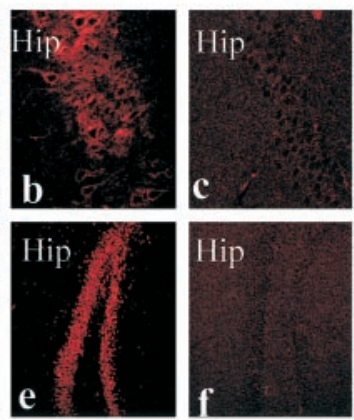

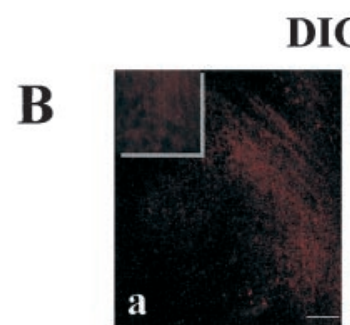

DIG-IGF-I
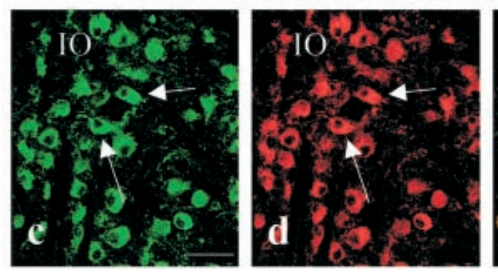
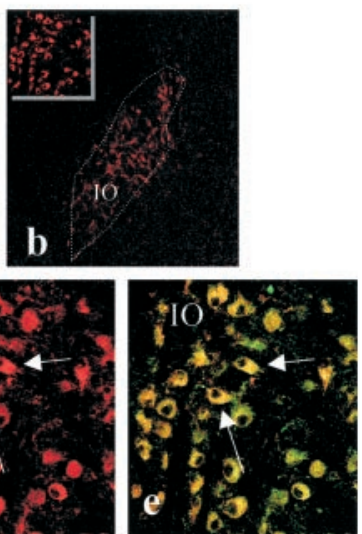

E

BDNF

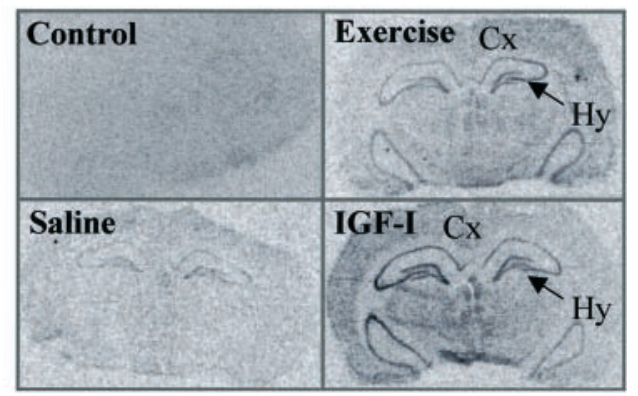

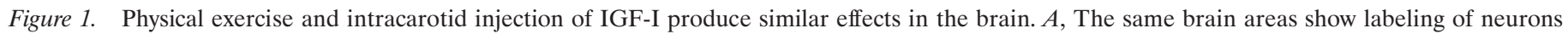

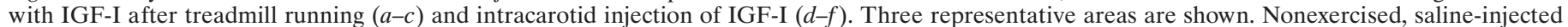

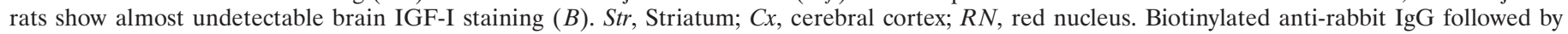

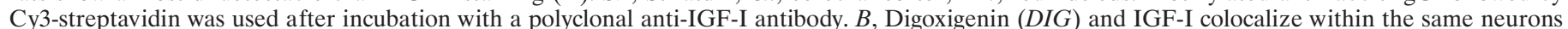

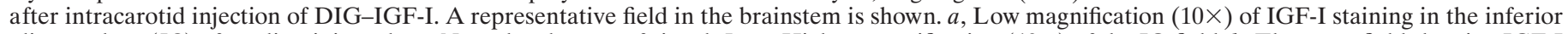

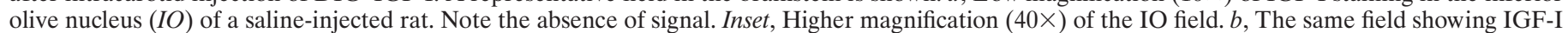

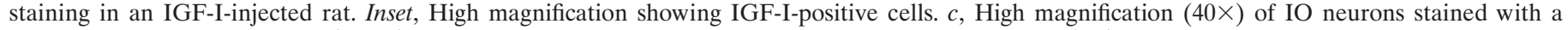

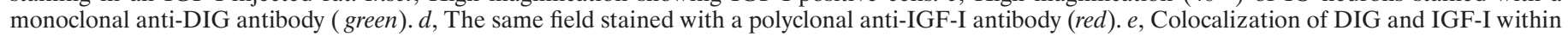

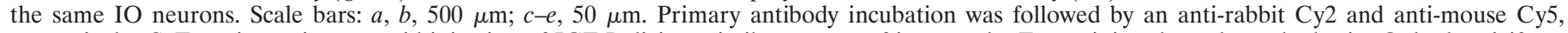

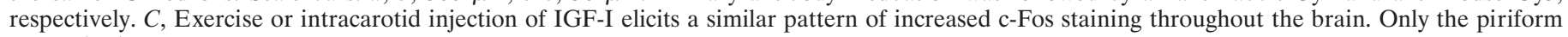

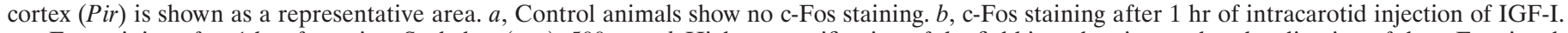

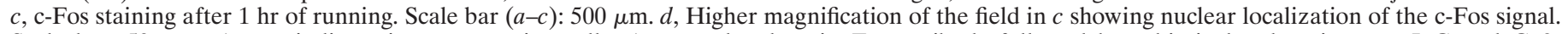

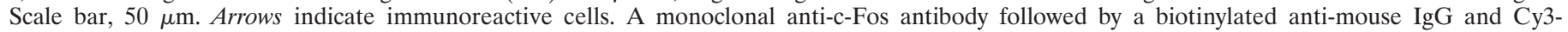

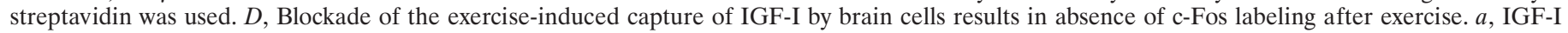

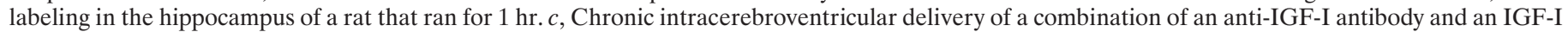

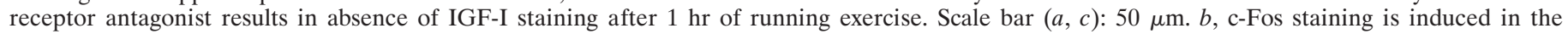

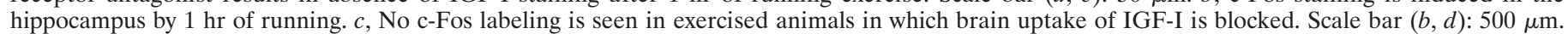

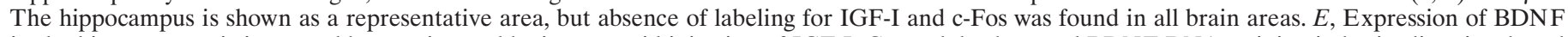

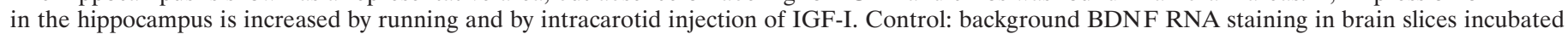

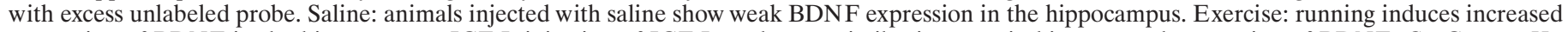

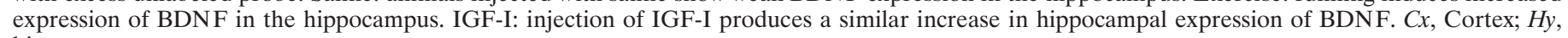
hippocampus.

peripheral administration (Poduslo et al., 1994; Reinhardt and Bondy, 1994), the pattern of brain staining after intracarotid injection of digoxigenin-labeled insulin is different from that observed after IGF-I and much weaker (data not shown).

We next analyzed possible routes of entry of blood-borne IGF-I into the brain. Based on previous observations (FernandezGalaz et al., 1998), we considered it likely that serum IGF-I enters the brain using the CSF pathway. We observed that CP epithelial cells, and subsequently ependymal cells of the ventricular walls, were prof usely labeled with DIG-IGF-I (Fig. $3 A$ ). CP cells show great abundance of IGF-I receptor immunoreactivity (Fig. $3 A$ ). When excess unlabeled IGF-I was injected into the CSF (100 $\mu \mathrm{g}$ per rat), the entry of labeled IGF-I from the blood was completely blocked (Fig. 3C). When saline was injected intracerebroventricularly, no blockade was seen (data not shown). More significant was the observation that levels of IGF-I in the CSF of animals that received intracarotid injection of $10 \mu \mathrm{g}$ of IGF-I were $400 \%$ higher $15 \mathrm{~min}$ after the injection than saline-injected rats $(p<$ 0.04 ) (Fig. 3B). Finally, delivery of labeled IGF-I into the lateral ventricle resulted in staining of the same brain areas that stained after intracarotid injection (Fig. 3D).

\section{Blood-borne IGF elicits changes in the electrophysiological properties of target neurons}

What is the functional significance, if any, of the entry of circulating IGF-I into the brain? Because increased neuronal staining 


\section{A}
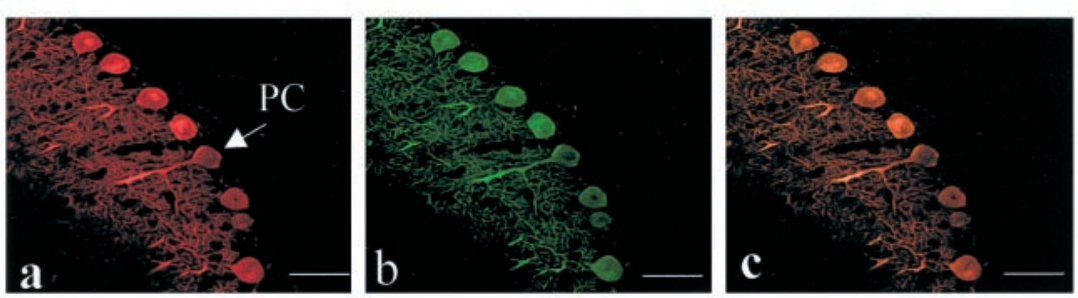

B

Figure 2. Blood-borne IGF-I is taken up by brain cells. $A$, Calbindin and IGF-I colocalize within neurons after intracarotid injection of DIG-IGF-I. A representative field in the cerebellar cortex is shown. $a$, Purkinje neurons stained with a polyclonal anti-IGF-I antibody (red). $b$, The same field stained with a monoclonal anti-calbindin antibody (green). $c$, Colocalization of calbindin and IGF-I within cerebellar Purkinje cells. Primary antibody incubation was followed by an anti-rabbit $\mathrm{Cy} 2$ and anti-mouse Cy5, respectively. B, Uptake of DIGIGF-I from serum is abolished by coinjection of excess unlabeled IGF-I but not by excess insulin. $a$, Inferior olive $(I O)$ neurons of a rat after intracarotid injection with DIG-IGF-I $(10 \mu \mathrm{g}) . b$, IO neurons of an animal injected with DIG-IGF-I (10 $\mu \mathrm{g})$ plus unlabeled IGF-I $(100 \mu \mathrm{g})$ show almost no immunoreactivity for digoxigenin. $c$, Coinjection of insulin $(2 \mathrm{mg})$ with DIG-IGF-I $(10 \mu \mathrm{g})$ results in partial displacement of digoxigenin label. Intracarotid injections were performed $1 \mathrm{hr}$ earlier. $C$, Accumulation of DIG-IGF-I by the brain is timedependent. A representative field of the cerebellar cortex is shown. $a$, No digoxigenin immunoreactivity is present in a saline-injected rat. Purkinje cells $(P C)$ in the cerebellar cortex stained for digoxigenin $5 \mathrm{~min}(b), 1 \mathrm{hr}(c)$, and $3 \mathrm{hr}(d)$ after intracarotid injection of DIG-IGF-I; $6 \mathrm{hr}(e)$ later, staining was absent. $G L$, Granule cell layer; $M L$, molecular layer. Scale bars, $50 \mu \mathrm{m}$. Polyclonal antiDIG antibody followed by biotinylated anti-rabbit IgG and Cy3-streptavidin was used. $D$, Brain levels of IGF-I are increased after exercise $(p<0.05)$ or after intracarotid injection of IGF-I ( $p=0.05)$, as compared with control levels.
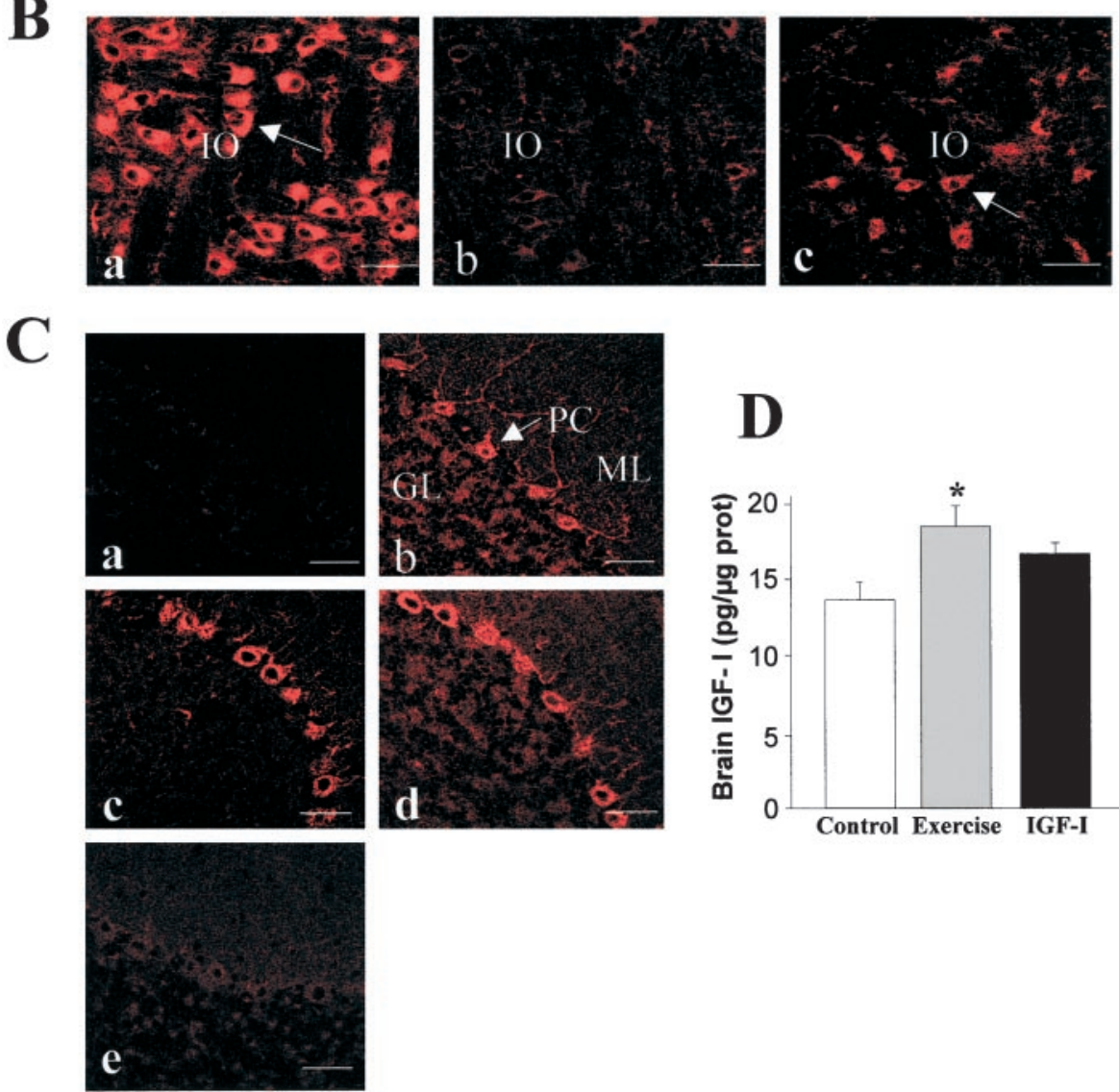

with c-Fos is associated with neuronal activation (Grassi-Zucconi et al., 1993), and intracarotid injection of IGF-I or exercise each markedly increased the number of c-Fos-positive neurons, we determined whether blood-borne IGF-I elicits changes in neuronal activity. We chose two different areas showing prominent accumulation of serum IGF-I: the cerebellar cortex and the DCN of the lower brainstem. Cerebellar Purkinje cells $(n=11)$ showed a spontaneous firing rate of $7.5 \pm 1.79$ spikes/sec, which gradually increased after intracarotid injection of IGF-I $(10 \mu \mathrm{g})$ in 9 of 11 cells tested. The increment was observed $15 \mathrm{~min}$ after intracarotid injection of IGF-I (14.1 \pm 4.62 spikes/sec) and reached statistical significance at $30 \mathrm{~min}(15.4 \pm 4.04$ spikes/sec; $p=$ $0.049)$ (Fig. 4A1). In some cases $(n=4)$, the increment in firing rate was observed up to $4 \mathrm{hr}$ after injection of IGF-I. No changes were seen when saline was injected (Fig. 4A2). Furthermore, IGF-I induced changes in parallel fiber-evoked potentials. A single stimulus applied to the cerebellar surface activated parallel fibers and evoked a well characterized field potential at the level of Purkinje cells (Eccles et al., 1966; Malenka and Kocsis, 1982). The field potential consisted of a brief negative wave followed by a longer lasting second negativity (Fig. 4B). The first negative
Table 1. Brain areas with c-Fos staining that have afferent and/or efferent projections to the corresponding areas showing IGF-I staining

\begin{tabular}{ll} 
Areas with c-Fos staining & Areas with IGF-I staining \\
\hline Piriform cortex $\rightarrow$ & Thalamus \\
Hippocampus: dentate gyrus $\rightarrow$ & Hippocampus: pyramidal cell layer \\
Striatum $\rightarrow$ & Striatum \\
Arcuate and paraventricular nuclei $\rightarrow$ & Supraoptic nucleus \\
Preoptic and supraoptic nuclei $\rightarrow$ & Brain stem \\
Vestibular nuclei $\rightarrow$ & Cerebellum: Purkinje cells \\
& Thalamus \\
Gigantocellular reticular and lateral & Cerebral cortex \\
reticular nuclei $\rightarrow$ & Cerebellum: central cerebellar nuclei, \\
& granule cell layer \\
& Olivary nuclei \\
& Cerebral cortex \\
Cerebellar cortex: granule cell layer $\rightarrow$ & Red nucleus \\
\hline
\end{tabular}

The $\rightarrow$ denotes connections to the corresponding IGF-I-positive area shown in the right column. 

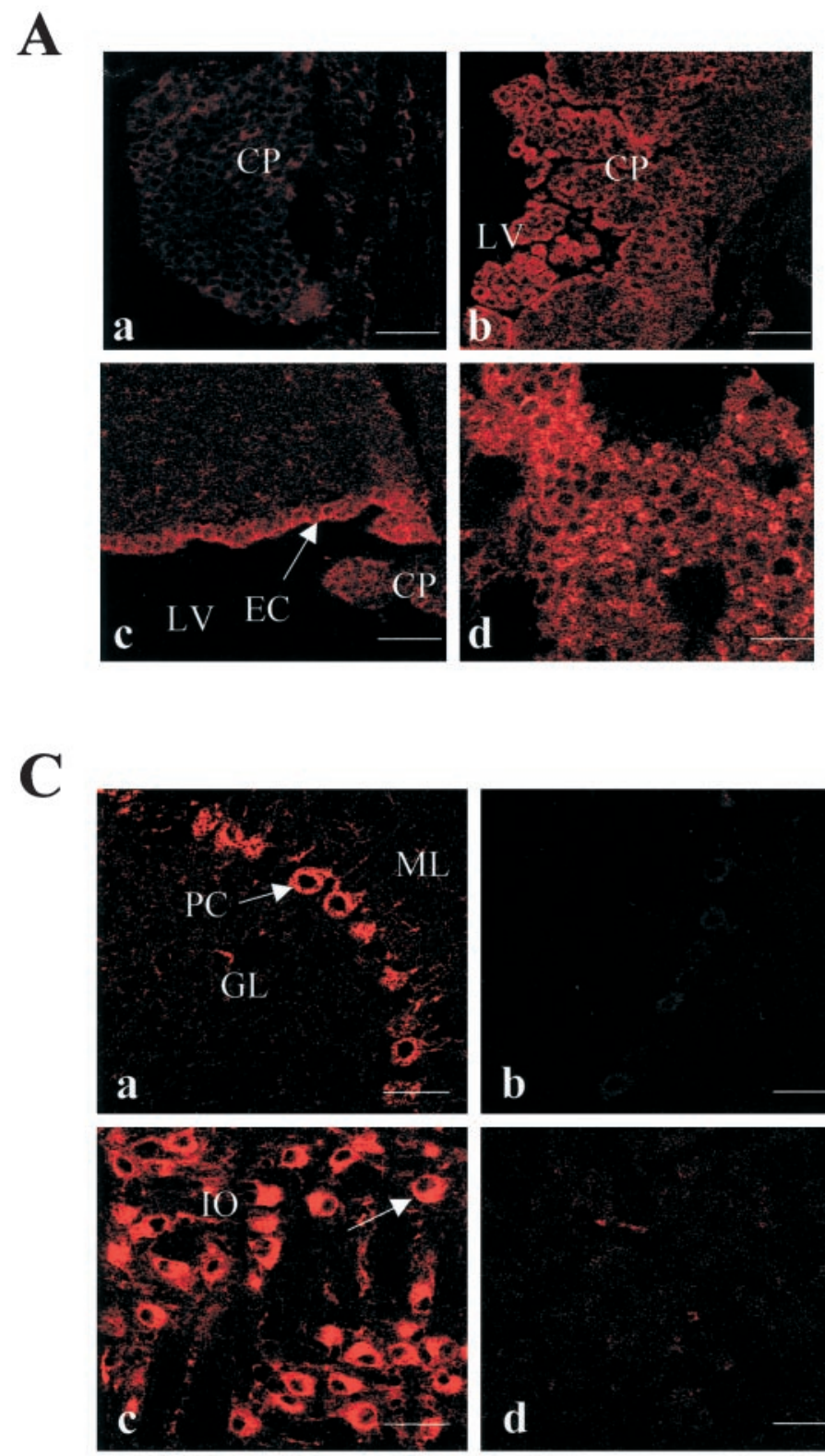
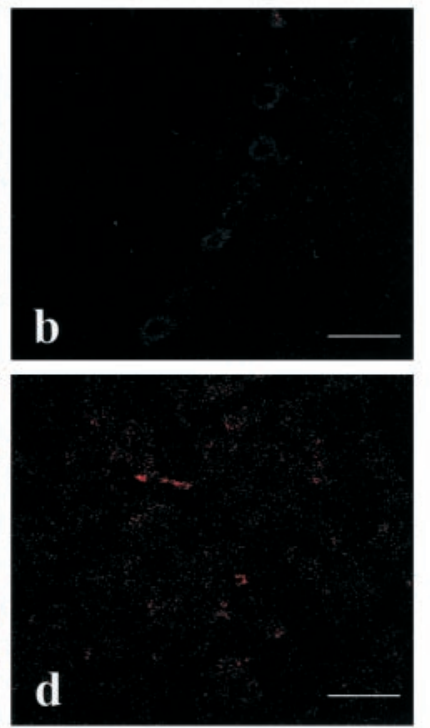

B

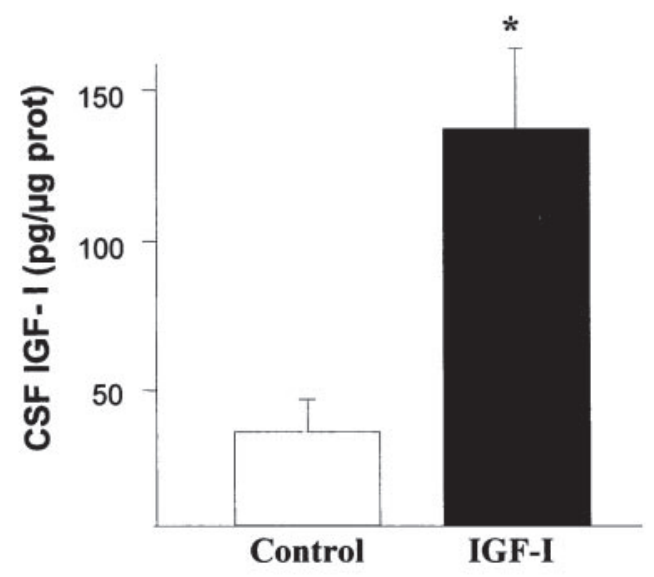

$\mathbf{D}$
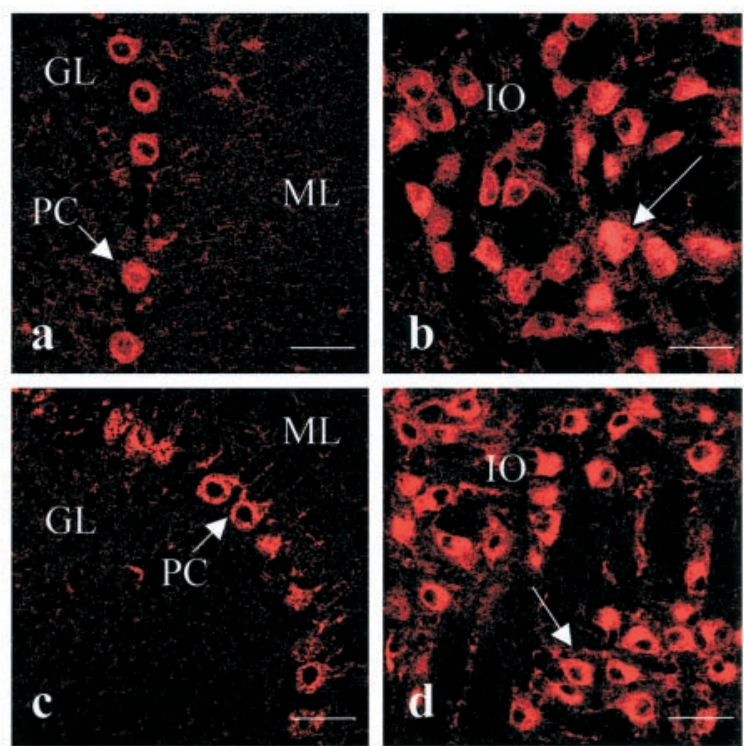

Figure 3. Serum IGF-I enters into the brain through the blood-CSF pathway. $A$, Epithelial cells of the choroid plexus $(C P)$ accumulate DIG-IGF-I and show IGF-I receptor immunoreactivity. $a$, Digoxigenin labeling of CP cells in the lateral cerebral ventricle $(L V)$ of a rat injected with DIG-IGF-I 5 min before. $b$, Ependymal cells $(E C)$ lining the wall of the ventricle show digoxigenin staining $1 \mathrm{hr}$ after injection of DIG-IGF-I. $c$, IGF-I receptor immunoreactivity in CP cells. $B$, Levels of immunoreactive IGF-I in the CSF were significantly increased 15 min after intracarotid injection of the peptide. ${ }^{*} p=0.03$ versus saline-injected control rats by Whitney test $(n=3)$. $C$, Injection of excess unlabeled IGF-I into the CSF displaces the uptake of serum DIG-IGF-I. Cerebellar Purkinje cells $(a)$ or IO neurons $(c)$ stained with DIG-IGF-I $1 \mathrm{hr}$ after intracarotid injection. DIG-IGF-I staining of Purkinje cells $(b)$ or IO neurons $(d)$ is absent after intracerebroventricular injection of $100 \mu \mathrm{g}$ unlabeled IGF-I. $D$, The pattern of neuronal uptake of IGF-I is similar after either intracerebroventricular $(a, b)$ or intracarotid injection of DIG-IGF-I $(c, d)$. Arrows indicate examples of positive cells. Scale bar, $50 \mu \mathrm{m}$. Antibodies that were used are as in previous figures.

wave is caused by the current generated by propagating impulses along the parallel fibers, whereas the second negative wave corresponds to the monosynaptic activation of Purkinje dendrites (Eccles et al., 1966). IGF-I injection induced an increase in the two components of the evoked field potentials in the nine cases that increased spontaneous activity after IGF-I (Fig. 4B, trace indicated with arrowheads). To quantify the changes elicited by IGF-I in parallel fiber-evoked field potentials, the areas of the first and second negative waves were measured (Fig. 4C). IGF-I increased the response area of both negative waves $(C 1, C 2) 15 \mathrm{~min}$ after the injection, although the increments were longer lasting in the first negative wave $(C 1)$. Saline injections $(n=3)$ did not elicit changes in evoked field potentials.

Because DCN cells also accumulate IGF-I (Fig. $5 A$ ), we tested whether IGF-I could change their response properties to natural somatosensory stimulation. Unit activity was recorded at rest and during stimulation of the receptive fields. IGF-I injection also induced a significant increase of the firing rate in 11 of $12 \mathrm{DCN}$ neurons, from $1.8 \pm 0.42$ to $2.8 \pm 0.52$ spikes $/ \mathrm{sec}$ after $15 \mathrm{~min}$ $(p=0.02)$. One hour later they returned to control levels (Fig. $5 B 1)$. As in the cerebellum, saline injection $(n=4)$ did not evoke changes in the firing rate (Fig. 5B2). IGF-I also increased the 


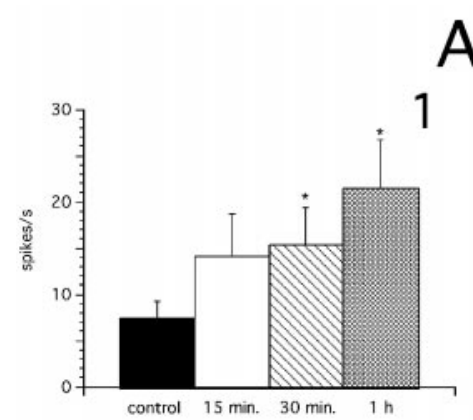

A
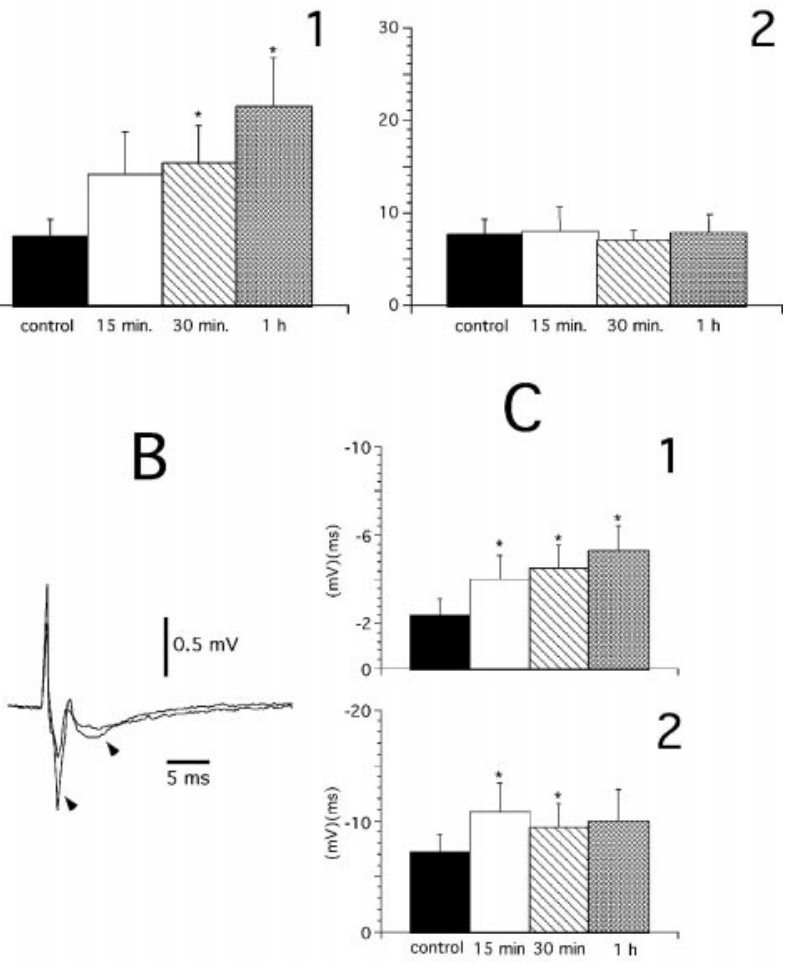

Figure 4. Intracarotid injection of IGF-I elicits long-lasting electrophysiological changes in cerebellar Purkinje cells. A1, Increase over time of mean spontaneous activity of Purkinje cells after intracarotid injection of IGF-I $(n=11)$. $A 2$, Control saline injection did not modify the firing rate over time $(n=3)$. $B$, Evoked field potentials in the cerebellum after parallel fiber stimulation. Two negative waves with short latencies were elicited. Arrowheads indicate the trace showing increased evoked potential 15 min after injection of IGF-I. $C$, Mean area of the first (1) and second (2) negative waves increase after IGF-I injection $(n=11)$. Baseline (control) levels were obtained before intracarotid injection of IGF-I. ${ }^{*} p<0.05$.

sensory responses of those DCN cells showing increased spontaneous activity after IGF-I $(n=11)$ (Fig. $5 C)$. To quantify changes elicited by IGF-I, evoked spikes per stimulus were measured in the $50 \mathrm{msec}$ time interval after stimulus onset. In control conditions, somatosensory stimulation evoked a mean of $0.89 \pm 0.13$ spikes per stimulus, which increased to $1.6 \pm 0.26$ spikes per stimulus after 15 min of IGF-I injection $(p=0.01)$. Changes elicited by IGF-I in DCN response properties were shorter than in cerebellar neurons, because $1 \mathrm{hr}$ after injection of IGF-I, levels were no longer significantly higher than baseline values in DCN cells but remained significantly elevated in cerebellar cells.

\section{DISCUSSION}

The present results indicate that increased uptake of circulating IGF-I by brain cells after physical exercise is involved in the effects of exercise on brain function. These findings also suggest a new physiological role for blood IGF-I through a novel mechanism that includes passage of circulating IGF-I into the brain, its accumulation by specific groups of neurons, stimulation of neuronal expression of c-Fos and BDNF, and long-lasting changes in neuronal activity. Our observations may lead to new therapeutic approaches and help explain previous findings of neuroprotective
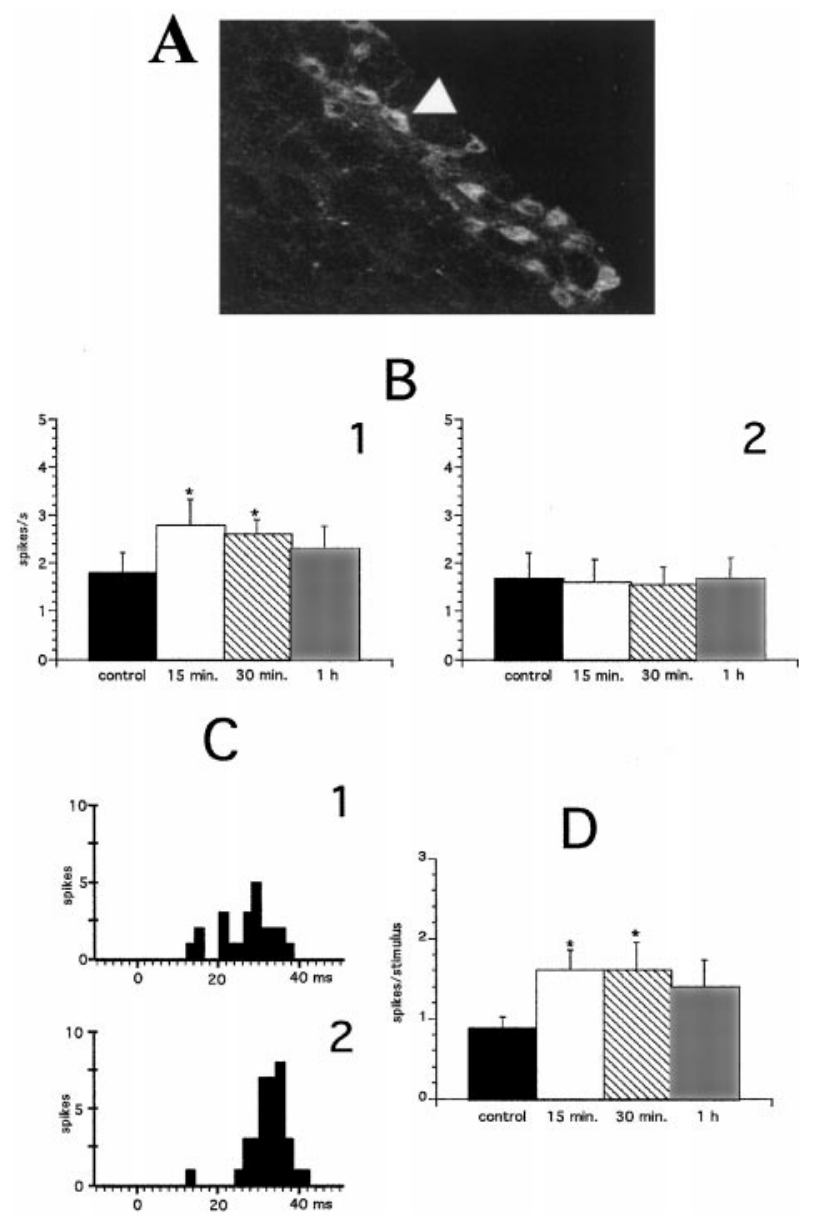

两。

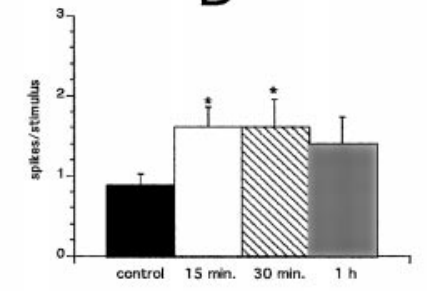

Figure 5. Intracarotid injection of IGF-I elicits electrophysiological changes in brainstem DCN neurons. $A$, DCN cells show intense IGF-I labeling after intracarotid injection of IGF-I. Similar IGF-I staining of these neurons is seen after exercise. Arrow indicates an IGF-Iaccumulating neuron. Scale bar, $50 \mu \mathrm{m}$. B1, Mean spontaneous activity of DCN neurons increases 15-30 min after IGF-I injection and tends toward baseline levels $1 \mathrm{hr}$ later. B2, Control saline injection did not modify the firing rate over time $(n=4)$. $C$, PSTHs $(20$ stimuli) of a representative cuneate nucleus cell before (1) and after (2) 15 min of intracarotid injection of IGF-I. The neuron responded to somatosensory stimulation delivered on the second digit of the hindpaw. Note the increase in the number of stimulus-evoked spikes after IGF-I. $D$, The number of spikes evoked by each somatosensory stimulus increased over time after injection of IGF-I $(n=12)$, indicating increased effectiveness of sensory stimulation. Control refers to values before injection of IGF-I. ${ }^{*} p<0.05$; $* * p<0.01$.

actions of IGF-I after peripheral administration (Fernandez et al., 1998; Pulford et al., 1999).

The observation that circulating growth factors access the brain is not new (Poduslo et al., 1994; Wagner et al., 1999). However, the physiological significance of this finding is obscured by the existence of the blood-brain barriers (Rubin and Staddon, 1999). Nevertheless, the presence of IGF-I receptors in choroid plexus epithelial cells (Marks et al., 1991) as well as in endothelial cells of brain capillaries (Frank et al., 1986) supports the possibility that IGF-I enters into the brain by either the blood-CSF or blood-brain interfaces. Our results indicate that the blood-CSF pathway is the major route used by serum IGF-I to access the brain. Thus, choroid plexus cells are heavily stained soon after intracarotid injection of IGF-I, whereas CSF levels of IGF-I increased dramatically after systemic administration of IGF-I. 
Furthermore, blockade of the uptake of serum IGF-I by excess IGF-I in the CSF, and a similar pattern of uptake after either intracarotid or intracerebroventricular administration, suggests a common route of entry.

Both treadmill running and intracarotid IGF-I induce higher levels of IGF-I in the brain, whereas serum levels remain unchanged. Because brain IGF-I mRNA levels do not change, the most likely explanation, although not the only one, is that increased brain levels are caused by increased uptake of IGF-I from serum. Because similar findings have been reported in muscle cells after acute exercise (Eliakina et al., 1997), it is conceivable that serum IGF-I levels remain unaltered after running because of the increased uptake of circulating IGF-I by target organs such as muscle and brain. In turn, increased brain uptake may be caused not only by increased circulating levels of IGF-I but also by the increased brain blood flow induced by exercise or IGF-I itself (Crill, 1989; Gillespie et al., 1997).

Uptake of systemic IGF-I by the brain is biologically relevant because physical exercise stimulates it. More significant is the observation that intracarotid injection of IGF-I mimics the effects of exercise on brain c-Fos and BDNF expression (Iwamoto et al., 1996; Liste et al., 1997) and that blockade of the uptake of IGF-I by brain cells results in blockade of the effects of exercise in the brain as determined by inhibition of increased c-Fos labeling. Furthermore, accumulation of peripheral IGF-I by areas involved in motor control, propioceptive sensations, or metabolic regulation, among others, suggests that circulating IGF-I activates brain areas that are involved in adaptive responses to physical exercise.

Only a minority of the cells that accumulate IGF-I after either exercise or exogenous administration of IGF-I express c-Fos. Thus, whether brain uptake of IGF-I and neuronal c-Fos expression are related events remains to be determined. The connectivity pattern of c-Fos-stained neurons with IGF-I-accumulating neurons includes both afferent and efferent connections between the two populations of cells (Table 1). This pattern is found both after exercise and after exogenous intracarotid injection of IGF-I, supporting the possibility of orthograde or retrograde signaling between the two populations of neurons. For example, cerebellar granule cells express c-Fos after IGF-I uptake by Purkinje cells postsynaptically connected to them.

Changes evoked by IGF-I in neuronal properties, such as those found in the cerebellar cortex and in DCN neurons, appear to have a physiological significance. Both types of IGF-I-accumulating neurons had increased sensitivity to afferent stimulation, together with an increased spontaneous firing rate. Previous results have shown that IGF-I produces changes in the electrophysiological properties of neurons through modulation of ion channels (Blair and Marshall, 1997). Other neurotrophic factors also modulate neuronal activity (Thoenen, 1995). However, to our knowledge this is the first evidence that IGF-I directly modulates neuronal activity in vivo. Interestingly, the time course of the effects of IGF-I on the two types of neurons that were analyzed is different. Although in DCN neurons the effects of IGF-I revert in $1 \mathrm{hr}$, in cerebellar Purkinje cells changes last several hours. The latter agrees with long-lasting effects of IGF-I on Purkinje cells (Castro-Alamancos and Torres-Aleman, 1993) and suggests that different mechanisms may underlie these changes. At any rate, changes produced by IGF-I on ion channels or on as yet undetermined intracellular targets seem to be of physiological relevance for regulation of synaptic transmission and firing pattern. Should IGF-I increase the activity of all target neurons in the brain, and this remains to be studied, we can envisage a situation in which the level of activity of many neurons throughout the brain could be potentially modulated by circulating IGF-I. This is in accordance with the proposed role of volume transmission in the brain, whereby humoral factors present in the blood-CSF-brain interstitial fluid compartment exert broad modulatory actions in the brain (Zoli et al., 1998).

In summary, serum IGF-I enters into the brain through the blood-CSF pathway and activates different target neurons throughout the brain in a long-term fashion. Physiological stimuli such as physical exercise and probably other as yet undetermined stimuli trigger an increased neuronal uptake of circulating IGF-I that can help explain part of the effects of exercise on brain function. In addition, the beneficial effects of physical exercise on recovery of brain function after injury could also be related to brain uptake of IGF-I because this peptide exerts powerful neuroprotective effects after peripheral administration (Fernandez et al., 1998; Pulford et al., 1999). Our results open a new avenue of research on the biological significance of circulating growth factors in the brain.

\section{REFERENCES}

Auletta M, Nielsen FL, Gammeltoft S (1992) Receptor-mediated endocytosis and degradation of insulin-like growth factor I and II in neonatal rat astrocytes. J Neurosci Res 31:14-20.

Blair LAC, Marshall J (1997) IGF-I modulates N and L calcium channels in a PI 3-kinase-dependent manner. Neuron 19:421-429.

Bondy CA, Werner H, Roberts CT, LeRoith D (1992) Cellular pattern of type-I insulin-like growth factor receptor gene expression during maturation of the rat brain: comparison with insulin-like growth factors I and II. Neuroscience 46:909-923.

Busiguina S, Chowen J, Argente J, Torres-Aleman I (1996) Specific alterations of the insulin-like growth factor I system in the cerebellum of diabetic rats. Endocrinology 137:4980-4987.

Castro-Alamancos CA, Torres-Aleman I (1993) Long-term depression of glutamate-induced gamma aminobutyric acid release in cerebellum by insulin-like growth factor I. Proc Natl Acad Sci USA 90:7386-7390.

Crill WE (1989) The milieu of the central nervous system. In: Text book of physiology (Patton HD, ed), pp 759-769. Philadelphia: Saunders.

Eccles JD, Llinas R, Sasaki K (1966) Parallel fiber stimulation and responses induced thereby in the Purkinje cells of the cerebellum. Exp Brain Res 1:17-39.

Eliakina A, Moromisato M, Moromisato D, Brasel JA, Roberts C, Cooper DM (1997) Increase in muscle IGF-I protein but not IGF-I mRNA after 5 days of endurance training in young rats. Am J Physiol 273: R1557-1561.

Fernandez AM, Garcia-Estrada J, Garcia-Segura LM, Torres-Aleman I (1997) Insulin-like growth factor I modulates c-Fos induction and astrocytosis in response to neurotoxic insult. Neuroscience 76:117-122.

Fernandez AM, Gonzalez de la Vega A, Torres-Aleman I (1998) Insulin-like growth factor restores motor coordination in a rat model of cerebellar ataxia. Proc Natl Acad Sci USA 95:1253-1258.

Fernandez AM, Gonzalez de la Vega A, Planas B, Torres-Aleman I (1999) Neuroprotective actions of peripherally administered insulinlike growth factor I on the injured olivo-cerebellar pathway. Eur J Neurosci 11:2019-2030.

Fernandez-Galaz MC, Torres-Aleman I, Garcia-Segura LM (1998) Receptor-mediated internalization of insulin-like growth factor I in neurons and glia of the central nervous system of the adult rat. Eur J Anat 2:147-158.

Ferry RJ, Katz LE, Grimberg A, Cohen P, Weinzimer SA (1999) Cellular actions of insulin-like growth factor binding proteins. Horm Metab Res 31:192-202.

Frank HJ, Pardridge WM, Morris WL, Rosenfeld RG, Choi TB (1986) Binding and internalization of insulin and insulin-like growth factors by isolated brain microvessels. Diabetes 35:654-661.

Gillespie CM, Markel AL, Martin AA (1997) Effects of insulin-like growth factor I and LR3IGF-I on regional blood flow in normal rats. J Endocrinol 155:351-358.

Gomez-Pinilla F, Dao I, Vannarith S (1997) Physical exercise induces FGF-2 and its mRNA in the hippocampus. Brain Res 764:1-8. 
Grassi-Zucconi G, Menegazzi M, Carcereri A, de Prati A, Bassetti A, Montagnese P, Mandile P, Cosi C, Bentivoglio M (1993) c-fos mRNA is spontaneously induced in the rat brain during the activity period of the circadian cycle. Eur J Neurosci 5:1071-1078.

Handelsman DJ, Spaliviero JA, Scott CD, Baxter RC (1987) Hormonal regulation of the peripubertal surge of insulin-like growth factor $\mathrm{I}$ in the rat. Endocrinology 120:491-496.

Hiney JK, Srivastava V, Nyberg CL, Ojeda SR, Les Dees W (1996) Insulin-like growth factor I of peripheral origin acts centrally to accelerate the initiation of female puberty. Endocrinology 137:3717-3728.

Iwamoto GA, Wappel SM, Fox GM, Buetow KA, Waldrop TG (1996) Identification of diencephalic and brainstem cardiorespiratory areas activated during exercise. Brain Res 726:109-122.

Jones JI, Clemmons CR (1995) Insulin-like growth factors and their binding proteins: biological actions. Endocr Rev 16:3-34.

Liste I, Guerra MJ, Caruncho HJ, Labandeira-Garcia JL (1997) Treadmill running induces striatal Fos expression via NMDA glutamate and dopamine receptors. Exp Brain Res 115:458-468.

Malenka RC, Kocsis JD (1982) Effects of GABA on stimulus-evoked changes in $\mathrm{K}^{+}$and parallel fiber excitability. J Neurophysiol 48: $608-621$.

Marks JL, Porte D, Baskin DG (1991) Localization of type I insulin-like growth factor receptor messenger RNA in the adult rat brain by in situ hybridization. Mol Endocrinol 5:1158-1168.

Neeper SA, Gomez-Pinilla F, Choi J, Cotman C (1995) Exercise and brain neurotrophins. Nature 373:109.

Paxinos G, Watson C (1997) The rat brain in stereotaxic coordinates, Ed 3. Sydney: Academic.

Poduslo JF, Curran GL, Berg CT (1994) Macromolecular permeability across the blood-nerve and blood-brain barriers. Proc Natl Acad Sci USA 91:5705-5709.

Pons S, Torres-Aleman I (1992) Basic fibroblast growth factor modulates insulin-like growth factor I, its receptor and its binding proteins in hypothalamic cultures. Endocrinology 131:2271-2278.

Pulford BE, Whalen LR, Ishii DN (1999) Peripherally administered insulin-like growth factor I preserves hindlimb reflex and spinal cord noradrenergic circuitry following a central nervous system lesion in rats. Exp Neurol 159:114-123.

Reinhardt RR, Bondy CA (1994) Insulin-like growth factors cross the blood-brain barrier. Endocrinology 135:1753-1761.

Rubin LL, Staddon JM (1999) The cell biology of the blood brain barrier. Annu Rev Neurosci 22:11-28.

Schwarz AJ, Brasel JA, Hintz RL, Mohan S, Cooper DM (1996) Acute effect of brief low- and high-intensity exercise on circulating insulin-like growth factor (IGF)-I, II, and IGF-binding protein 3 and its proteolysis in young healthy men. J Clin Endocrinol Metab 81:3492-3497.

Thoenen H (1995) Neurotrophins and neuronal plasticity. Science 270:593-598.

Van Praag H, Kempermann G, Gage FH (1999) Running increases cell proliferation and neurogenesis in the adult mouse dentate gyrus. Nat Neurosci 2:266-270.

Wagner JP, Black IB, DiCicco-Bloom E (1999) Stimulation of neonatal and adult brain neurogenesis by subcutaneous injection of basic fibroblast growth factor. J Neurosci 19:6006-6016.

Werther GA, Abate M, Hogg A, Cheesman H, Oldfield B, Hards D, Hudson P, Power B, Freed K, Herington AC (1990) Localization of insulin-like growth factor-I mRNA in rat brain by in situ hybridization: relationship to IGF-I receptors. Mol Endocrinol 4:773-778.

Yakar S, Liu JL, Stannard B, Butler A, Accili D, Sauer B, LeRoith D (1999) Normal growth and development in the absence of hepatic insulin-like growth factor I. Proc Natl Acad Sci USA 96:7324-7329.

Zoli M, Torri C, Ferrari R, Jansson A, Zini I, Fuxe K, Agnati LF (1998) The emergence of the volume transmission concept. Brain Res Rev 26:136-147. 